\title{
İşitme cihazı kullanan çocuklarda gürültüde konuşmayı anlama becerisinin değerlendirilmesi: Preliminer sonuçlar*
}

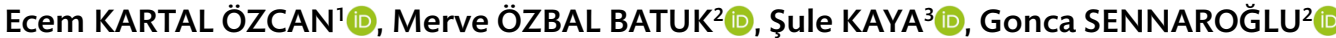 \\ 'Sağlık Bilimleri Üniversitesi Gülhane Sağlık Bilimleri Fakültesi Odyoloji Bölümü, Ankara, Türkiye \\ ${ }^{2}$ Hacettepe Üniversitesi Sağlık Bilimleri Fakültesi Odyoloji Bölümü, Ankara, Türkiye \\ ${ }^{3}$ Ankara Yıldırım Beyazıt Üniversitesi Sağlık Bilimleri Fakültesi Odyoloji Bölümü, Ankara, Türkiye
}

\section{ÖZET}

\begin{abstract}
Amaç: Gürültülü ortamlar, tıpkı yetişkinler gibi çocukların da günlük yaşamının bir parçasıdır. İşitme kaybı olan ve işitme cihazı kullanan çocuklar, normal işiten yaşıtlarına göre gürültünün olumsuz etkilerine daha hassastır. Bu çalışmanın amacı işitme cihazı kullanan çocukların gürültüde konuşmayı anlama performanslarının değerlendirilmesi ve normal işiten yaşıtlarıyla karşılaştırılmasıdır.
\end{abstract}

Gereç ve Yöntemler: Çalışmaya 6-12 yaşları arasında, bilateral ortadan ileri dereceye kadar simetrik sensörinöral işitme kaybı olan ve bilateral kulak arkası işitme cihazı kullanan 5 çocuk dahil edilmiştir. Türkçe HINT-C'nin 4 farklı koşulu uygulanmış ve her koşul için bir konuşmayı anlama eşiği (KAE) belirlenmiştir.

Bulgular: İşitme cihazı kullanan çocukların, yaşlarından bağımsız olarak normal işiten yaşıtlarıyla eşit performansa ulaşabilmek için ihtiyaç duydukları SGO, tüm test koşulları için daha yüksek bulunmuştur. Genel olarak normal işiten çocuklarda da görüldüğ̈̈ gibi işitme kayıplı çocukların ortalama $G_{\text {ön }}$ skoru, ortalama $G_{\text {sẵ }}$ ve $\mathrm{G}_{\mathrm{sol}}$ skorlarından daha yüksek elde edilmiştir.

Sonuç: $\mathrm{Bu}$ araştırmanın sonuçları bilateral simetrik ortadan ileri dereceye kadar işitme kaybı olan çocukların normal işiten yaşıtlarına kıyasla, sınıf ortamına benzer ortamlarda daha kötü konuşmayı anlama skorları elde ettiklerini ortaya koymuştur. Sonuçlarımız, uygun rehabilitasyon ve takipler için yol gösterici olmuştur.

Anahtar Kelimeler: gürültü, gürültüde konuşmayı anlama, işitme kaybı, işitme cihazı, pediatrik odyoloji, HINT, HINT-C

Cite this article as: Kartal Özcan, E., Özbal Batuk, M., Kaya, Ş., Sennaroğlu, G. (2021). İşitme cihazı kullanan çocuklarda gürültüde konuşmayı anlama becerisinin değerlendirilmesi: Preliminer sonuçlar. Turk J Audiol Hearing Res, 4(2):45-50.

\begin{abstract}
Assessment of speech perception in noise in children with hearing aids: Preliminary results*

Objective: Noisy environments are a part of the daily life of children, just like adults. Children with hearing loss who wear hearing aids are more susceptible to the negative effects of noise than their normalhearing peers. This study aims to evaluate the speech recognition in noise performance of hearing aid users and compare them with their normal-hearing peers.
\end{abstract}

Material and Method: Five children aged 6-12 years with bilateral moderate to severe symmetrical sensorineural hearing loss and using bilateral behind-the-ear hearing aids were included in the study. 4 different conditions of the Turkish HINT-C were applied, and a speech recognition threshold (SRT) is determined for each condition.

Results: Regardless of their age, the SRT needed by children with hearing aids to achieve equal performance with their normal-hearing peers was found to be higher for all test conditions. As seen in children with normal hearing in general, the mean noise front score of the children with hearing loss was higher than the mean noise right and noise left scores.

Conclusion: The results of this study revealed that children with bilaterally symmetrical moderate to severe hearing loss achieved poor speech recognition scores in environments similar to the classroom environment, compared to their normal-hearing peers. Our results guided appropriate rehabilitation and follow-up.

Keywords: noise, speech recognition in noise, hearing loss, hearing aid, pediatric audiology, HINT, HINT-C

\section{Giris}

Sözlü iletişim neredeyse her zaman arka plan gürültüsü varlığında gerçekleşir. Trafik, rakip konuşmacılar, klima ve bilgisayar fanları yaygın gürültü kaynaklarına örnek olarak verilebilir (Assmann \& Summerfield, 2004). Dinleyiciler başarılı bir iletişim için gürültüyle başa çıkmalıdır. Gürültü varlığında konuşulanları anlamak, periferik ve santral işitme ile birlikte bilişsel fonksiyonların normal olmasıyla sağlanabilmektedir (Wong, Uppunda, Parrish, \& Dhar, 2008).
Kalıcı çocukluk çă̆ 1 işitme kaybının varlığı, çocukların konuşma ve dil gelişimi üzerinde olumsuz etkiye sahiptir. Erken çocuklukta konuşma algısının gelişimi; rakip seslerin var olduğu karmaşık akustik ortamlarda, ilgili akustik bilgi ve dil bilgisine ulaşabilmekle yakından ilişkilidir (Ching et al., 2018). Erken teşhis ve erken müdahaleye rağmen, işitme kayıplı çocukların dil gelişiminde ve günlük yaşamda dezavantajlı oldukları bildirilmektedir (Ching et al., 2010). İşitme kaybı olan ve/ 
veya işitme cihazı kullanan çocuklar, normal işitenlere kıyasla, gürültülü ortamlardan biri olan sinıflarda daha fazla problemle karşılaşırlar. İşitme cihazları ve koklear implantlar işitilebilirliği iyileştirse de, normal işiten kişilere göre arka plan gürültüsü varlığında konuşulanları anlamak zor olmaya devam etmektedir (Brännström, von Lochow, Lyberg Åhlander, \& Sahlén, 2020; Iglehart, 2020; Torkildsen, Hitchins, Myhrum, \& Wie, 2019). Koklear işitme kaybında, işitsel sinyal işlemleme değişir, pitch ve loudness algısı bozulur. Sensorinöral işitme kaybının özellikleri; düşük duyarlılık, anormal şiddet algısı (loudness recruitment), düşük frekans seçiciliği ve temporal rezolüsyondur. Bunların sonucu olarak eşik üstü işitme ve gürültüde konuşmayı anlama bozulmaktadır (Celesia, 2013; McArdle, Wilson, \& Burks, 2005; Moore, 2008).

Gürültüde konuşmayı anlama, işitme cihazı kullanan hafif-orta derecede sensörinöral işitme kaybına sahip kişilerin başlıca şikayetlerinden biridir. Sinyal-gürültü oranı (SGO), konuşma seviyesi ile gürültü seviyesi arasındaki fark olarak tanımlanır. Negatif bir SGO, gürültünün konuşmadan daha yüksek olduğu ve dinlemenin daha zor olabileceği anlamına gelir (Torkildsen et al., 2019). SGO açısından zorlu (SGO'nun negatif veya negatife yakın olduğu durumlar) akustik ortamlarda dinleme ve konuşmayı anlama yeteneğinin ölçülmesi, geleneksel olan ve sessiz koşullarda gerçekleştirilen saf ses odyometrisi ve konuşma odyometrisi değerlendirmelerinden çok daha fazlasını içermelidir (DL \& Abrams, 2018). Literatürdeki çalışmalar, sensorinöral işitme kaybı olan bireylerin konuşmayı anlama becerilerinin normal işitenlere kıyasla, özellikle gürültü varlığında büyük ölçüde bozulduğunu açıkça göstermiştir (Carhart \& Tillman, 1972; Carhart \& Young, 1976). Bu durumun, kullanılan arka plan gürültüsünün türünden (ör. konuşma spektrum gürültüsü, genlik modülasyonlu beyaz gürültü vs.) bağımsız olarak geçerli olduğu bildirilmiştir. Sensörinöral işitme kaybı varlığında, sessiz koşulda işitme cihazı kullanılarak normal işiten bireylerin performansına eşit performans elde edilebilirken, gürültülü koşulda bu mümkün olmamaktadır (Olsen \& Tillman, 1968). Sonuç olarak, saf ses eşiklerinin belirlenmesi ve sessiz koşulda uygulanan konuşma odyometrisine ek olarak, gürültü varlığındaki ölçümler yapılması önerilmektedir. Bu ölçümler ile, sensörinöral işitme kayıplı hastanın, günlük yaşamdaki karmaşık dinleme ortamlarında karşılaştığı iletişim sorunlarına daha iyi bir bakış sağlanabilir. Bununla birlikte elde edilen sonuçlar, bireye uygun işitme cihazı seçiminde etkili olabilir (Carhart \& Tillman, 1972).

Gürültülü ortamlar, tıpkı yetişkinler gibi çocukların da günlük yaşamının bir parçasıdır. Çocukların günün büyük bir kısmını geçirdikleri sınıf ortamlarının karmaşık akustik durumu; öğretmen, diğer çocuklar, sınıf içindeki cihazlar ve yankılanma özellikleriyle tanımlanabilir (Neuman \& Hochberg, 1983; Schafer, 2010) . Sınıf ortamının bu özelliklerinin çocukların performans1 üzerinde olumsuz etkiler oluşturabileceği düşünüldügünde, çocuklarda gürültüde konuşmayı anlama becerisinin ölçülmesi önemli hale gelmektedir. Çocuklarda sözlü ve yazılı dilin edinimi için önemli olan periferik ve santral işitme sisteminin değerlendirilmesinde, gürültüde konuşmayı anlama testlerinin kullanımı önemlidir (Aarabi, Jarollahi, Badfar, Hosseinabadi, \& Ahadi, 2016; de Carvalho, Novelli, \& Colella-Santos, 2017; Percy-Smith et al., 2020). Okul çağındaki işitme kayıplı çocuklar akademik müfredatları takip etmeli, sosyalleşmeyi öğrenmelidir ve bunlar genellikle gürültü varlığında gerçekleşir. Gürültüde konuşmayı anlama becerisinin ölçülmesi, çocuğun gürültülü bir sınıftaki konuşmaları anlamasına, buna bağlı olarak da akademik başarısına ilişkin bilgi sağlayabilmektedir (Schafer, 2010).

Pediatrik popülasyonda kullanılan gürültüde konuşmayı anlama testleri arasında; HINT-C (Hearing in Noise Test for Children), BKB-SIN (Bamford-Kowal-Bench Speech-in-Noise Test), PSI (Pediatric Speech Intelligibility Test), Azbio, Babybio testleri sayllabilir (Jerger \& Jerger, 1984; Nilsson, Soli, \& Gelnett, 1996; Nyquette, 2005; Spahr et al., 2014; Spahr et al., 2012). HINTC'nin Türkçe versiyonu 2019 yılında Kartal ve ark. tarafından yüksek lisans tezi olarak yayınlanmıştır. Çalışmanın sonuçlarına göre farklı yaş gruplarının HINT-C skorları; 6 yaş grubu için, SK: $27,08 \mathrm{~dB}, \mathrm{G}_{\text {ön }}: 1,09 \mathrm{~dB} \mathrm{SGO}, \mathrm{G}_{\text {sağ }}:-3,54 \mathrm{~dB}$ SGO ve $\mathrm{G}_{\text {sol }}:-3,62 ; 8$ yaş grubu için, $\mathrm{SK}: 25,08 \mathrm{~dB}, \mathrm{G}_{\text {ön }}:-0,21 \mathrm{~dB}$ SGO, $\mathrm{G}_{\text {saă }}:-4,24 \mathrm{~dB}$ $\mathrm{SGO}, \mathrm{G}_{\mathrm{sol}}:-4,85 \mathrm{~dB}$ SGO ve 10 yaş grubu için, $\mathrm{SK}: 24,56 \mathrm{~dB}, \mathrm{G}_{\text {ön }}$ : $-0,73 \mathrm{~dB}$ SGO, $\mathrm{G}_{\mathrm{sag}}:-4,91 \mathrm{~dB} \mathrm{SGO}, \mathrm{G}_{\text {sol }}:-5,08 \mathrm{~dB}$ SGO şeklindedir. SRM avantajları 6,8 ve 10 yaş grupları için sırasıyla 4,67, 4,33, 4,26 dB'dir (KARTAL, 2019). Gürültüde Konuşmayı Anlama Testi'nin pediatrik versiyonu, 6-12 yaş arasındaki çocukların gürültüde konuşma anlama becerilerinin değerlendirilmesinde kullanılabilir. İşitme cihazı kullanan çocukların konuşmayı anlama becerileri, normal işiten çocuklardan farklılık gösterir. $\mathrm{Bu}$ becerilerin düzenli kullanım ve rehabilitasyon sayesinde normal işiten yaşıtları ile benzer seviyeye gelmesi mümkündür.

Literatürde daha önce, hedef ses ve gürültünün farklı yönlerden geldiği koşullarda işitme cihazı kullanan çocukların performansının değerlendirilmesi ihtiyacına dikkat çekilmiştir (Ching, Van Wanrooy, Dillon, \& Carter, 2011). Bu ihtiyaçtan yola çıkılarak mevcut araştırmanın amacı, 6-12 yaşları arasında, bilateral orta, orta ileri veya ileri derecede simetrik işitme kaybı olan işitme cihazı kullanıcısı çocukların gürültüde konuşmayı anlama performanslarının değerlendirilmesi, normal işiten yaşıtlarıyla karşılaştırılması ve elde edilen skorlara göre gerekli öneriler ve müdahalelerin yapılmasıdır. Değerlendirme için bağlamsal ipuçlarını taşıyan materyallerin olduğu Türkçe HINT-C testi kullanılmıştır. Bağlamsal ipuçları ihtiyaç duyulan SGO'lar için iyileşme sağlamaktadır. Ayrıca, dinleme ortamı, sinyal ve gürültünün çeşitli açılardan sunulmasını sağlayacak şekilde düzenlemiştir.

Bilateral normal işiten bireyler için, sinyalin bir kulak tarafindan geldiği durumda, sinyalin tam karşıdan geldiği duruma göre dinlemenin daha kolay olduğu ve konuşmayı anlama becerisinin iyileştiği bildirilmiştir (Bess \& Tharpe, 1986). Çocuklarla 
yapılan bu çalışmada da, sağ ve sol kulakların saf ses eşikleri ve işitme cihazlı eşiklerinin; gürültünün önden $\left(\mathrm{G}_{\text {ön }}\right)$, sağdan $\left(\mathrm{G}_{\text {sağ }}\right)$ ve soldan $\left(\mathrm{G}_{\text {sol }}\right)$ geldiği koşullardaki performansı etkilemesi beklenmekteydi. Gürültü koşulları içinde elde edilen en iyi skorun $\mathrm{G}_{\text {ön }}$ koşulunda veya işitme cihazlı eşikleri daha kötü olan kulak tarafından gürültünün geldiği koşulda olacağı düşünülmüştü.

\section{GEREÇ VE YÖNTEMLER}

\section{Bireyler}

Çalışmaya 6-12 yaşları arasında, bilateral orta, orta ileri veya ileri derecede simetrik sensörinöral tipte işitme kaybı olan ve anadili Türkçe olan 5 çocuk dahil edilmiştir. Katılımcıların hepsi bilateral kulak arkası işitme cihazı ve biopar malzemeden üretilmiş kulak kalıbı kullanmaktadır. Bilateral işitme cihazlı eşikleri konuşma alanı içinde (20-45 dB) yer alan katılımcılar dahil edilmiştir. Yaş grubu HINT-C'nin uygulama alanına göre belirlenmiştir. Tanılanmış bir ek engel veya gelişimsel gecikmesi olmak, kulak cerrahisi geçirmiş olmak ve aktif orta kulak patolojisi dahil edilmeme kriterleri olarak belirlenmiştir. Çalışmaya katılan bireyler ve ebeveynleri çalışmanın kapsamı ve amacı hakkında bilgilendirilmiş ve yazılı onamları alınmıştır. Çalışmamız Helsinki Deklerasyonu prensiplerine uygun şekilde yürütülmüştür.

\section{Odyolojik Değerlendirme ve İşitme Cihazı Ayarı}

Her çocuğa saf ses işitme odyometrisi ve timpanometrik değerlendirme yapılmıştır. İşitme eşikleri sağ, sol kulak ve işitme cihazlı eşikler olarak belirlenmiştir. Tüm katılımcılar, kişisel işitme cihazları birden fazla kanal ve banda sahip olacak şekilde seçilmiştir. Doğrulama prosedürü için katılımcıların gerçek kulak ölçümleri yapılmış olup DSL v5.0 formülü hedeflerine mümkün olduğunca yakın eşleştirilmiştir.

\section{HINT-C Prosedürü}

Çalışmada, serbest alandaki hoparlörler ile adaptif olarak Türkçe HINT-C koşullarının uygulanması için tasarlanan HINT-PV yazılımı kullanılmıştır. JBL Control one hoparlörler aracılığıyla adaptif test protokolü kullanılmış ve her katılımcıya dört test koşulu uygulanmıştır. Hoparlörlerin kalibrasyonu Wintact markalı ve WT1357 model sound level meter (SLM) ile yapılmıştır. Hoparlörlerin yerleşimi Şekil 1'de gösterilmiştir. Değerlendirilen koşullar; sessiz koşul ve gürültü kaynağının yerine göre tanımlanan üç gürültü koşuludur. Bu 4 koşul; Sessiz Koşul (SK) (konuşma $\left.0^{\circ}\right)$, Gürültü Önde $\left(\mathrm{G}_{\text {ön }}\right.$ ) (konuşma ve gürültü $0^{\circ}$ ), Gürültü Sağda $\left(\mathrm{G}_{\text {sağ }}\right)$ (konuşma $0^{\circ}$, gürültü $\left.90^{\circ}\right)$, Gürültü Solda $\left(\mathrm{G}_{\mathrm{sol}}\right)$ (konuşma $0^{\circ}$, gürültü $270^{\circ}$ ) şeklindedir. Bunlara ek olarak, katılımcıların $\mathrm{G}_{\text {taraf }} \mathrm{KAE}$ değerlerini elde etmek için, Gsağ ve Gsol KAE değerlerinin ortalaması alınmış ve SRM, Gön KAE değerinden $G_{\text {taraf }}$ KAE değeri çıkarılarak elde edilmiştir.

Konuşma kaynağının yeri testin her koşulu için doğrudan katılımcının önünde $\left(0^{\circ}\right)$ ve baş merkezine $1 \mathrm{~m}$ uzaklıktadır. Katılımcı, gürültü koşullarından sağ gürültü koşulu için $\left(\mathrm{G}_{\text {sağ }}\right)$ sol hoparlöre, sol gürültü koşulu $\left(G_{\text {sol }}\right)$ için sağ hoparlöre

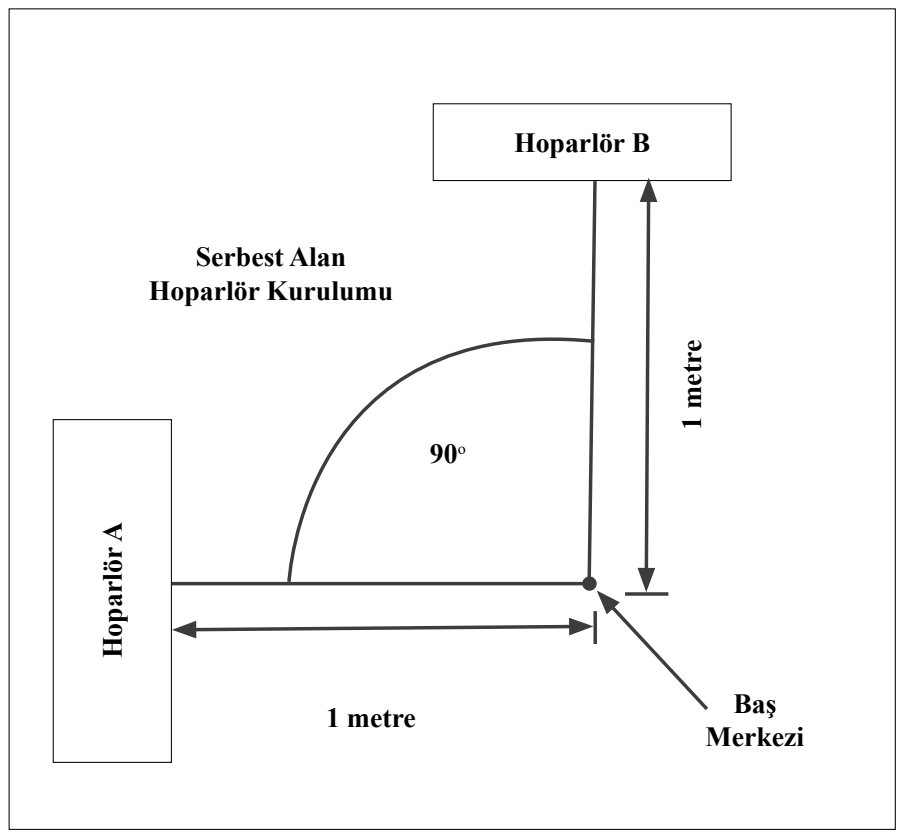

Şekil 1. Hoparlör Yerleşimi

bakacak şekilde konumlandırılmıştır. Hoparlörler birbiriyle $90^{\circ}$ açı yapacak şekilde ve çocuğun kulak seviyesi yüksekliğinde yerleştirilmiştir. Serbest alan için hoparlör kalibrasyonu yapılırken SLM mikrofonu da aynı şekilde konumlandırılmıştır.

Her katılımcıya tüm Türkçe HINT-C test koşulları, sessiz koşul ile başlamak üzere, gürültülü koşullar randomize şekilde olarak uygulanmıştır. Liste sırası ve listeler içindeki cümle sırası kılavuzda önerildiği üzere yazılım tarafından rastgele belirlenmiştir. Gürültülü koşullardaki gürültü seviyesi sabit olmakla birlikte (65 dB), konuşma seviyesi çocuğun doğru veya yanlış cevaplarına göre (yazılım tarafından) ayarlanmıştır. İlk dört cümlenin sunum seviyesini ayarlamak için 4 dB'lik adımlar, daha sonra 2 dB'lik adımlar kullanılmıştır. Konuşma anlama eşiği (KAE), dinleyicinin cümlelerin \%50'sini doğru bir şekilde tekrar edebildiği ortalama SGO olarak tanımlanmış olup (artikülasyon hataları ve ek kelimeler göz ardı edilerek), 5. ve 11. cümlelerin ortalaması alınarak yazılım tarafından tahmin edilmiştir (11. cümle için sunum seviyesi 10. cümleden elde edilmektedir.).

Katılımcı sayısının az olması nedeniyle bulgularımız olgu serisi şeklinde sunulmuştur.

\section{BULGULAR}

\section{Olgu 1}

Yenidoğan işitme taramasından geçmiş olan 6 yaşındaki hastanın işitme kaybının progresif olduğu düşünülmüştür. Hastanın yüksek frekanslara doğru artan ileri derecede sensörinöral işitme kaybı mevcuttur (Şekil 2). 3 yaşında tanılanarak bilateral cihazlandırılan hastanın konuşması anlaşılırdır ve akademik başarısının iyi olduğu aile tarafından belirtilmiştir. Hasta özel eğitime devam etmekte, 
FM sistem kullanmamaktadır. Hastanın HINT-C koşullarında elde ettiği ortalama skorlar Tablo 1'de gösterilmektedir.

\section{Olgu 2}

Yenidoğan işitme taramasından geçmiş olan hasta 11 yaşındadır. Bilateral orta derecede sensörinöral işitme kaybı olan hasta (Şekil 2), 5 yaşında tanılanmış ve bilateral cihazlandırılmıştır. Sınıfta en ön sırada oturduğunu, herhangi bir problem yaşamadığını belirtmiştir ve FM sistem kullanmamaktadır. Hastanın HINT-C koşullarında elde ettiği ortalama skorlar Tablo 1'de gösterilmektedir.

\section{Olgu 3}

Yenidoğan işitme taramasında sol kulaktan geçerek sağ kulaktan iki kez kalan 9 yaşındaki hastanın bilateral orta derecede sensörinöral işitme kaybı mevcuttur (Şekil 2). 3 yaşında tanılanarak bilateral cihazlandırılmıştır. Cihazlarını düzenli olarak kullanan hasta FM sistem kullanmamaktadır. Hastanın HINT-C koşullarında elde ettiğgi ortalama skorlar Tablo 1'de gösterilmektedir.

\section{Olgu 4}

Prematüre doğan hasta yeni doğan işitme taramasından ve tekrarından bilateral kalmıştır. 6 yaşındaki hasta 4 aylıkken bilateral cihazlandırılmış ve 7 aylıkken özel eğitim almaya başlamıştır. Kreşe devam etmekte olan hastanın bilateral yüksek frekanslara doğru artan orta ileri derecede sensörinöral işitme kaybı mevcuttur (Şekil 2). Hasta FM sistem kullanmamaktadır. Hastanın HINT-C koşullarında elde ettiği ortalama skorlar Tablo 1 'de gösterilmektedir.

\section{Olgu 5}

Yenidoğan işitme taramasından bilateral kalmış olan 9 yaşındaki hasta 2,5 yaşında cihazlandırılmıştır. Hastanın bilateral orta derecede sensörinöral işitme kaybı mevcuttur (Şekil 2). Hasta cihazlandırıldığından beri özel eğitime devam etmektedir. Akademik başarısının iyi olduğu söylenen hastanın ebeveyni, FM sistemi öğretmen problemi nedeniyle kullanamadıklarını belirtmiştir. Hastanın HINT-C koşullarında elde ettiği ortalama skorlar Tablo 1'de gösterilmektedir.

\section{TARTIŞMA}

İşitme cihazı kullanan çocukların skorları Türkçe HINT-C'nin yaşa özgü normatif değerleriyle karşılaştırıldığında, yaşlarından bağımsız olarak normal işiten yaşıtlarıyla eşit performansa ulaşabilmek için ihtiyaç duyulan SGO, tüm test koşulları için daha yüksek bulunmuştur (KARTAL, 2019). Çalışmada yer alan

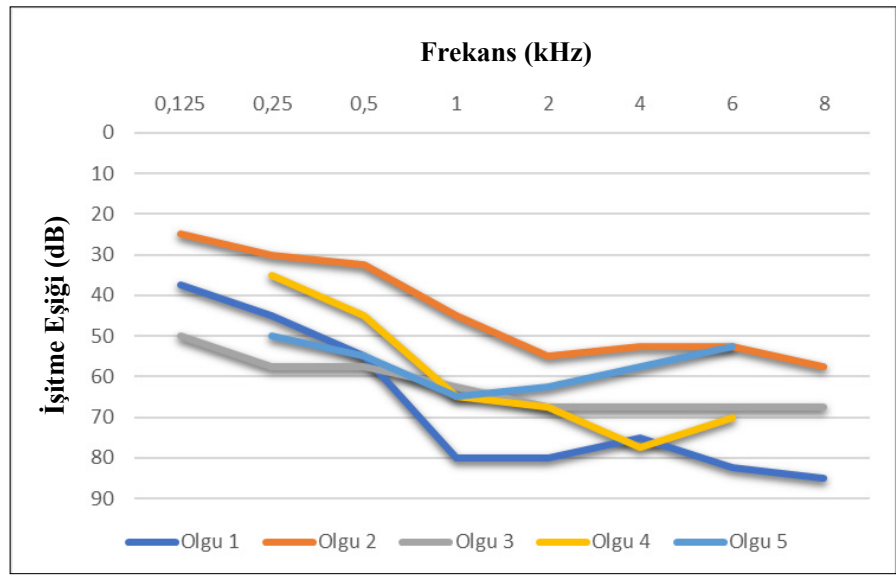

Şekil 2. Katılımcıların Hava Yolu İşitme Eşikleri

beş çocuktan ikisi, gürültünün iyi kulağa geldiği duruma göre $\mathrm{G}_{\text {ön }}$ koşulunda daha iyi skor elde etmiştir. Genel olarak normal işiten çocuklarda da görüldüğü gibi işitme kayıplı çocukların ortalama $G_{\text {ön }}$ skoru, ortalama $G_{\text {să̆ }}$ ve $G_{\text {sol }}$ skorlarından daha yüksek (daha düşük performans) elde edilmiştir.

$\mathrm{Bu}$ araştırmanın sonuçları bilateral simetrik orta, orta ileri veya ileri derecede işitme kaybı olan çocukların normal işiten yaşıtlarına kıyasla, sınıf ortamına benzer ortamlarda daha kötü konuşmayı anlama skorları elde ettiklerini ortaya koymuştur. Gürültüde konuşmayı anlama becerisi; işitme kaybı derecesi azaldıkça, işitme cihazlı eşikler iyileştikçe ve yaş arttıkça iyileşmektedir. Literatürdeki çalışmalar, işitme cihazı/koklear implant kullanan çocukların normal işiten çocuklara kıyasla, gürültüde konuşmayı anlama performansının daha iyi SGO durumunda bile önemli ölçüde düşük olduğunu bildirmektedir (Brännström et al., 2020; von Lochow, Lyberg-Åhlander, Sahlén, Kastberg, \& Brännström, 2018). Sonuçlarımız bahsedilen çalışmalarla tutarlıdır. İşitme kaybının düşük performans ile ilişkili olmasının bir diğer sebebi, kelime bilgisi ve/veya dil bilgisi becerilerinde eksikliğe yol açması olabilir (Torkildsen et al., 2019). Buna dayanarak çalışmamızdaki yenidoğan işitme taramasından kalmış olan hastaların geç tanılanması ve yanlış yönlendirilmesinin, gürültüde konuşmayı anlama becerilerinin normal işiten yaşıtlarıyla ile eşit seviyeye gelememesine sebep olabileceği düşünülmektedir.

$\mathrm{Bu}$ çalışma; işitme cihazından iyi yarar gören, dil gelişimi yaşıtları ile uyumlu çocuklarda bile gürültüde konuşmayı anlama becerilerinin normal işiten yaşıtlarından daha kötü olduğunu göstermiştir. İşitme cihazı kullanan çocuklar, normal

Tablo 1. Çalışmaya Katılan Olguların Ortalama HINT-C Skorları (KAE)

\begin{tabular}{|c|c|c|c|c|c|}
\hline & SK (dB) & $G_{\ddot{o n n}}(d B S G O)$ & $G_{\text {sağ }}(d B S G O)$ & $\mathrm{G}_{\mathrm{sol}}(\mathrm{dB} \mathrm{SGO})$ & SRM Avantajı \\
\hline Olgu 1 & 40,9 & 5,4 & 4,3 & 4,9 & 0,8 \\
\hline Olgu 2 & 41,5 & $-0,6$ & $-1,8$ & 1,0 & 0,2 \\
\hline Olgu 3 & 42,0 & 6,2 & 1,3 & 3,3 & 1,6 \\
\hline Olgu 4 & 44,7 & 8,7 & 6,7 & 3,8 & 3,6 \\
\hline Olgu 5 & 42,1 & 2,3 & 1,5 & 3,1 & 0 \\
\hline
\end{tabular}

KAE: Konuşmayı Anlama Eşiği, SK: Sessiz Koşul, SGO: Sinyal Gürülttü Oranı, $\mathrm{G}_{\text {ön }}$ : Gürültü Önde, $\mathrm{G}_{\mathrm{sağg}}$ : Gürültü Sağda, $\mathrm{G}_{\mathrm{sol}}$ : Gürülttü Solda, SRM: Spatial Release from Masking 
işiten yaşıtları ile eşit performansa ulaşabilmek için daha büyük SGO'lara ihtiyaç duymaktadır. Buna ek olarak, bilateral işitme kayıplı olan çocuklar beklendiği gibi, sinyal daha iyi işiten kulağa geldiğinde daha iyi performans göstermektedir.

Türkçe yaşa özgü normatif değerlere bakıldığında, normal işiten çocukların her zaman için $G_{\text {ön }}$ koşuluna kıyasla $G_{\text {sağ }}$ ve $G_{\text {sol }}$ koşulunda daha yüksek SGO ihtiyacı duyduğu görülmektedir. $\mathrm{Bu}$ bilgiye dayanarak normal işiten çocukların konuşma ve gürültünün mekansal olarak ayrılması sonucu SRM avantajından faydalandıkları söylenebilir. Mevcut çalışmanın sonuçlarına bakıldığında ise, işitme cihazlı çocuklarda bu durumun değişebileceği görülmüştür. Test sonuçları paylaşılan 5 çocuktan ikisi, gürültünün iyi kulak tarafından geldiği duruma göre $G_{\text {ön }}$ koşulunda daha iyi skorlar elde etmiştir. Özellikle yüksek frekans işitme eşiklerinin ve işitme cihazlı eşiklerin sağ ve sol kulak arasındaki küçük farklılıklarının buna sebep olabileceği düşünülmektedir. Mevcut çalışmanın sonuçlarıyla tutarlı olarak Ching ve arkadaşları (Ching et al., 2011), 3-12 yaş arası çocuklarda gürültüde kelime ve cümle anlamayı değerlendirmiş; işitme cihazı kullanan çocuklardan bazılarının hedef ve gürültü kaynağının mekansal ayrımından fayda sağladığını, bazılarının ise mekansal ayrım sonucu dezavantaj sergilediğini bildirmişlerdir.

Gürültülü ortamda konuşmayı anlamanın özellikle cümleler kullanılarak test edilmesi, işitme kayıplılar için gerçek dinleme durumlarındaki performansı daha iyi yansıtır. Uygulanan testler bir kişinin işitmesinin ve kullandığı teknolojinin yaşam boyu değerlendirmesinde kullanılabilir (Percy-Smith et al., 2020). Türkçe HINT-C, bu ölçüm için kullanılabilecek uygun bir araçtır. Elde edilen sonuçlara göre, işitme kayıplı çocukların sınıf içinde en iyi dinleyebilecekleri yerde oturmaları gerektiği göze çarpmaktadır. Türkçe HINT-C'nin koşullarında elde edilen KAE skorlarına göre bir çocuğun sınıf içinde oturması gereken en uygun sira ve taraf belirlenebilir. Bununla birlikte, ders esnasında işitme kayıplı çocuk ve öğretmenin sınıf içinde birbirlerine göre konumları değişiklik gösterecektir. İşitme kayıplı çocukların her koşul için daha iyi SGO'ya ihtiyaç duydukları göze alındığında, en iyi dinleyebilecekleri yerde oturmalarının bile yeterli olmayacağı öngörülebilir. Mevcut çalışmadan da anlaşılabileceği gibi, yardımcı işitme cihazlarının kullanımı yaygın değildir. Maddi olanaklar ve/veya öğretmen ile anlaşmazlıklar bu duruma sebep gösterilebilir. Günlük yaşamdaki ve özellikle okul ortamındaki işitsel performansın artırılabilmesi için işitme kayıplı çocuklara mutlaka sinyal gürültü oranını iyileştiren yardımcı dinleme cihazlarının kullanımı önerilmelidir (Crandell, 1993; Ruscetta, Arjmand, \& Pratt, 2005). Gelecek çalışmalarda, bu çalışmada sunulan preliminer sonuçlar göz önüne alınarak, işitme kaybı başlangıç yaşı ve derecesi, kullanılan işitme cihazının özellikleri gibi faktörler Türkçe HINT-C ile değerlendirilmelidir. Buna ek olarak Türkçe HINT-C ile yardımcı işitme cihazlarının etkinliği de değerlendirilebilir.

\section{SONUC}

Türkçe HINT-C ile işitme cihazı kullanan çocukların gerçek yaşamdaki konuşmayı anlama becerilerine daha iyi bir izlenim sağlanabilir. Bununla birlikte Türkçe HINT-C, işitme cihazı ve/veya koklear implant adaylığının değerlendirilmesinde ve uygulama sonrası takiplerde kullanılabilir. Gürültüde konuşma algısı değerlendirmeleri işitme cihazı, FM sistem ve/veya sınıf ortamı akustik düzenlemeleri ihtiyacına yönelik fikir verebilir. İşitme cihazı teknolojisi, yönlü mikrofonlar ve FM sistemleri kullanarak zorlu akustik koşullarda konuşma algısını iyileştirmeye yardımcı olabilir (Anderson, Goldstein, Colodzin, \& Iglehart, 2005).

Ethics Committee Approval: The study was carried out in accordance with the principles of the Declaration of Helsinki.

Informed Consent: Written consent was obtained from the participating children and their parents.

Peer-review: Externally peer-reviewed.

Author Contributions: Concept - GS, MOB, SK, EKO; Design - GS, MOB, SK, EKO Supervision - GS, MOB; Resources - GS, MOB, SK, EKO; Data Collection and/or processing - MBO, EKO; Analysis and/or interpretation - GS, MOB, EKO; Literature Search - MOB, EKO; Writing Manuscript - MOB; EKO.

Conflict of Interest: No conflict of interest.

Financial Disclosure: None.

*Presentation: This study was presented as an oral presentation at the $9^{\text {th }}$ International Symposium on Hearing Aids and Implants held on October 10-13, 2019.

Etik Kurul Onayı: Çalışma Helsinki Deklerasyonu prensiplerine uygun olarak gerçekleştirilmiştir.

Hasta Onamı: Katılımcılar çalışmanın kapsamı ve amacı hakkında bilgilendirilmiş olup; okuryazar çocuklar için kendileri ve ebeveynlerinden, okuryazar olmayan çocukların ise ebeveynlerinden yazılı izinleri alınmıştır.

Hakem Değerlendirmesi: Dış Bağımsız.

Yazar Katkıları: SK, EKO; Tasarım - GS, MOB, SK, EKO; Denetleme - GS, MOB; Kaynak GS, MOB, SK, EKO; Veri Toplanması ve/veya İşlemesi - MOB, EKO; Analiz ve/veya Yorum - GS, MOB, EKO; Literatür Taraması - MOB, EKO; Yazıyı Yazan - MOB, EKO.

Çıkar Çatışması: Yoktur.

Finansal Destek: Finansal destek kullanılmamıştır.

*Sunum: Bu çalışma 10-13 Ekim 2019 tarihinde düzenlenmiş olan 9. Uluslararası İşitme Cihazları ve İmplantlar Sempozyumu'nda sözlü bildiri olarak sunulmuştur.

\section{KAYNAKLAR}

Aarabi, S., Jarollahi, F., Badfar, S., Hosseinabadi, R., \& Ahadi, M. (2016). Speech perception in noise mechanisms.

Anderson, K. L., Goldstein, H., Colodzin, L., \& Iglehart, F. (2005). Benefit of S/N enhancing devices to speech perception of children listening in a typical classroom with hearing aids or a cochlear implant. Journal of Educational Audiology, 12, 14-28

Assmann, P., \& Summerfield, Q. (2004). The perception of speech under adverse conditions. In Speech processing in the auditory system (pp. 231-308): Springer.

Bess, F. H., \& Tharpe, A. M. (1986). An introduction to unilateral sensorineural hearing loss in children. Ear and Hearing, 7(1), 3-13.

Brännström, K. J., von Lochow, H., Lyberg Åhlander, V., \& Sahlén, B. (2020). Passage comprehension performance in children with cochlear implants and/ or hearing aids: The effects of voice quality and multi-talker babble noise in relation to executive function. Logopedics Phoniatrics Vocology, 45(1), 15-23.

Carhart, R., \& Tillman, T. W. (1972). Individual consistency of hearing for speech across diverse listening conditions. Journal of Speech and Hearing Research, 15(1), 105-113.

Carhart, R., \& Young, L. (1976). Development of test procedures for evaluation of binaural hearing aids. Bulletin of prosthetics research.

Celesia, G. G. (2013). Disorders of Peripheral and Central Auditory Processing1: Disorders of Peripheral and Central Auditory Processing (Vol. 10): Elsevier Health Sciences. 
Ching, T. Y., Crowe, K., Martin, V., Day, J., Mahler, N., Youn, S., . . Orsini, J. (2010). Language development and everyday functioning of children with hearing loss assessed at 3 years of age. International journal of speech-language pathology, 12(2), 124-131.

Ching, T. Y., Van Wanrooy, E., Dillon, H., \& Carter, L. (2011). Spatial release from masking in normal-hearing children and children who use hearing aids. The Journal of the acoustical society of America, 129(1), 368-375.

Ching, T. Y., Zhang, V. W., Flynn, C., Burns, L., Button, L., Hou, S., . . . Van Buynder, P. (2018). Factors influencing speech perception in noise for 5-yearold children using hearing aids or cochlear implants. International journal of audiology, 57(sup2), S70-S80.

Crandell, C. C. (1993). Speech recognition in noise by children with minimal degrees of sensorineural hearing loss. Ear and Hearing, 14(3), 210-216.

de Carvalho, N. G., Novelli, C. V. L., \& Colella-Santos, M. F. (2017). Evaluation of speech in noise abilities in school children. International journal of pediatric otorhinolaryngology, 99, 66-72.

DL, D. J., \& Abrams, H. (2018). Audiologic considerations for people with normal hearing sensitivity yet hearing difficulty and/or speech-in-noise problems.

Iglehart, F. (2020). Speech perception in classroom acoustics by children with hearing loss and wearing hearing aids. American journal of audiology, 29(1), 6-17.

Jerger, S., \& Jerger, J. (1984). Pediatric speech intelligibility test: Auditec of St. Louis.

KARTAL, E. (2019). Çocuklar için Gürültüde Konuşmayı Anlama Testi'nin Türkçe Yaşa Özgü Normlarının Belirlenmesi.

McArdle, R. A., Wilson, R. H., \& Burks, C. A. (2005). Speech recognition in multitalker babble using digits, words, and sentences. Journal of the American Academy of Audiology, 16(9), 726-739.

Moore, B. C. (2008). The role of temporal fine structure processing in pitch perception, masking, and speech perception for normal-hearing and hearingimpaired people. Journal of the Association for Research in Otolaryngology, 9(4), 399-406.

Neuman, A. C., \& Hochberg, I. (1983). Children's perception of speech in reverberation. The Journal of the acoustical society of America, 73(6), 21452149 .
Nilsson, M., Soli, S., \& Gelnett, D. (1996). Development of the hearing in noise test for children (HINT-C). Los Angeles, CA: House Ear Institute, 1-9.

Nyquette, P. (2005). BKB-SIN Speech-in-Noise Test. Elk Grove Village, IL: Etymotic Research.

Olsen, W. O., \& Tillman, T. W. (1968). Hearing aids and sensorineural hearing loss. Ann Otol Rhinol Laryngol, 77(4), 717-726. doi:10.1177/000348946807700410

Percy-Smith, L., Wischmann, S., Josvassen, J. L., Hallstrøm, M., Laplante-Lévesque, A., Sorgenfrei, M. G., \& Caye-Thomasen, P. (2020). Evaluation of a sentence test in noise in children with hearing impairment. Danish medical journal, 67(1).

Ruscetta, M. N., Arjmand, E. M., \& Pratt, S. R. (2005). Speech recognition abilities in noise for children with severe-to-profound unilateral hearing impairment. International Journal of Pediatric Otorhinolaryngology, 69(6), 771-779.

Schafer, E. C. (2010). Speech perception in noise measures for children: A critical review and case studies. Journal of Educational Audiology, 16, 4-15.

Spahr, A. J., Dorman, M. F., Litvak, L. M., Cook, S., Loiselle, L. M., DeJong, M. D. ... Gifford, R. H. (2014). Development and validation of the pediatric AzBio sentence lists. Ear and Hearing, 35(4), 418.

Spahr, A. J., Dorman, M. F., Litvak, L. M., Van Wie, S., Gifford, R. H., Loizou, P. C., ... Cook, S. (2012). Development and validation of the AzBio sentence lists. Ear and Hearing, 33(1), 112.

Torkildsen, J. v. K., Hitchins, A., Myhrum, M., \& Wie, O. B. (2019). Speech-in-noise perception in children with cochlear implants, hearing aids, developmental language disorder and typical development: The effects of linguistic and cognitive abilities. Frontiers in Psychology, 10, 2530.

von Lochow, H., Lyberg-Åhlander, V., Sahlén, B., Kastberg, T., \& Brännström, K. J. (2018). The effect of voice quality and competing speakers in a passage comprehension task: performance in relation to cognitive functioning in children with normal hearing. Logopedics Phoniatrics Vocology, 43(1), 11-19.

Wong, P. C., Uppunda, A. K., Parrish, T. B., \& Dhar, S. (2008). Cortical mechanisms of speech perception in noise. 